\title{
DESIGN AND STABILITY OF LONG SPAN RAILWAY ARCH BRIDGE
}

The bow-string arch bridge across the Vah River was designed on the main Slovak railway line. Total length of the bridge is almost $451 \mathrm{~m}$, while the lengths of two main spans are $124.8 \mathrm{~m}$. To analyse behaviour of the bridge, spatial transformation model was developed using FEM software. The Eurocodes were applied for all verification procedures. Bridge global analysis and verification of arches against buckling is discussed in more detail. The variation of upper bracing system and its influence on out-of-plane buckling of the arches is presented. Together with an architecture point of view, a minimum load amplifier to reach the elastic instability $a_{c r}$ is used to estimate the suitability of the bracings.

Keywords: Arch bridges, bow-string girder, buckling, stability of arches, bracings.

\section{Introduction}

The main traffic lines in Slovakia, which have been included into European railway corridors, are under reconstruction and modernization during last decade. The speed $160 \mathrm{~km} / \mathrm{h}$ is required, at least, [1]. In this context, our department has participated on design and processing of project documentation of several railway bridges. Given the nature of the line, majority of touched bridges are of small and medium spans [2]. But, there are also several bridges, which are dominant due to their spans or used technology [3]. Considering great number of relatively large bridges around Nosicka Dam, the concept of maximum utilisation of arched bridges in this area has been agreed during preliminary design work in order to achieve consistent bridge structures in this attractive location. One of such bridges, located in the line section between towns Puchov and Povazska Bystrica, will be bridging the Nosicky Canal at the Vah River. Experiences and remarks from design of this bridge are presented in this paper. The main attention is paid to global analysis and verification of the arches under buckling and the associated system of bracing arches.

\section{Conception of the bridge structure}

\subsection{Preliminary design}

The bridge will cross the Nosicky Water Canal just directly behind the railway station Puchov under very acute crossing angle $19.5^{\circ}$. A demand of the State Navigation Administration

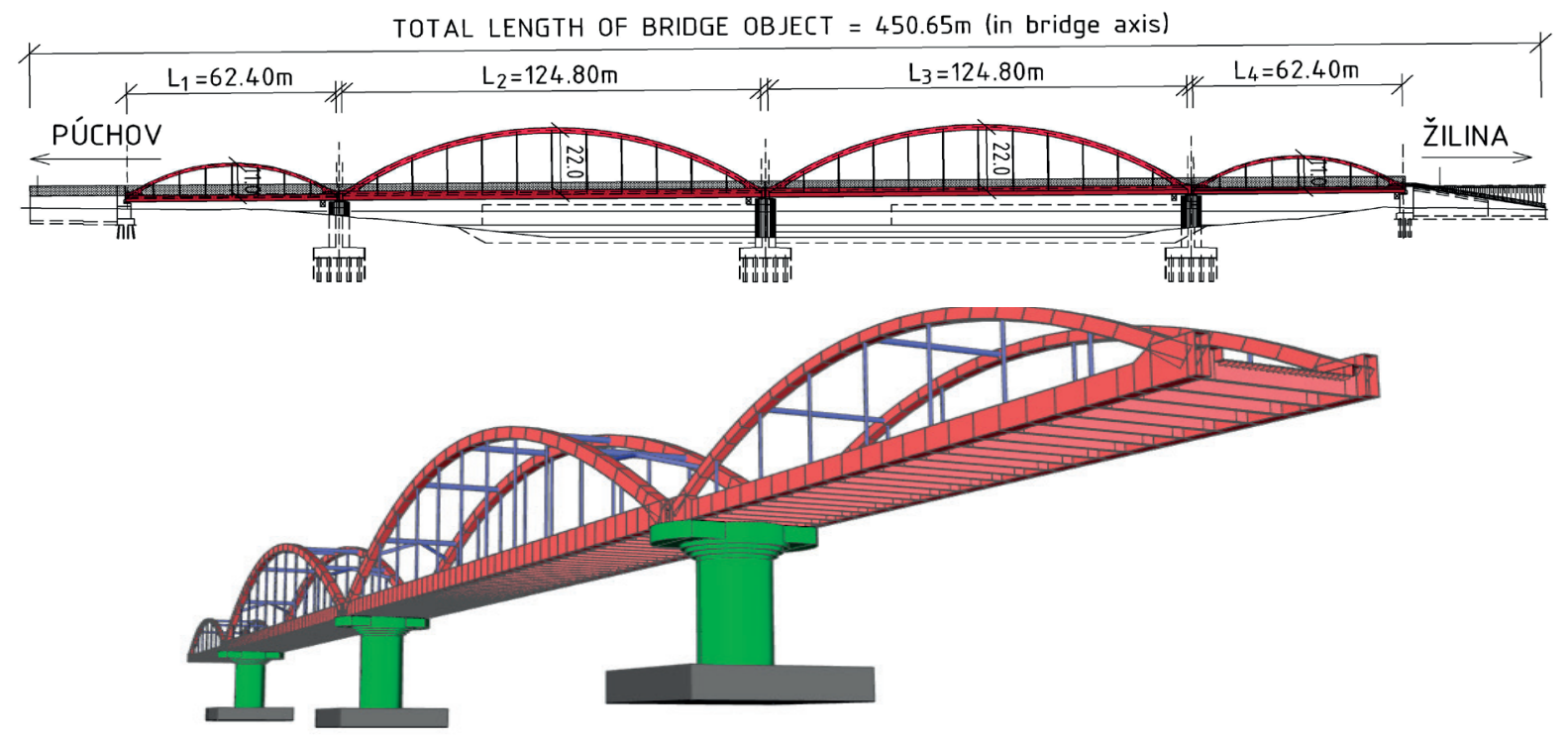

Fig. 1 Longitudinal view and FEM model visualisation of the bridge - the first proposal

\footnotetext{
* Josef Vican, Jozef Gocal, Jaroslav Odrobinak, Richard Hlinka

Department of Structures and Bridges, Faculty of Civil Engineering, University of Zilina, Slovakia, E-mail: vican@fstav.uniza.sk
} 


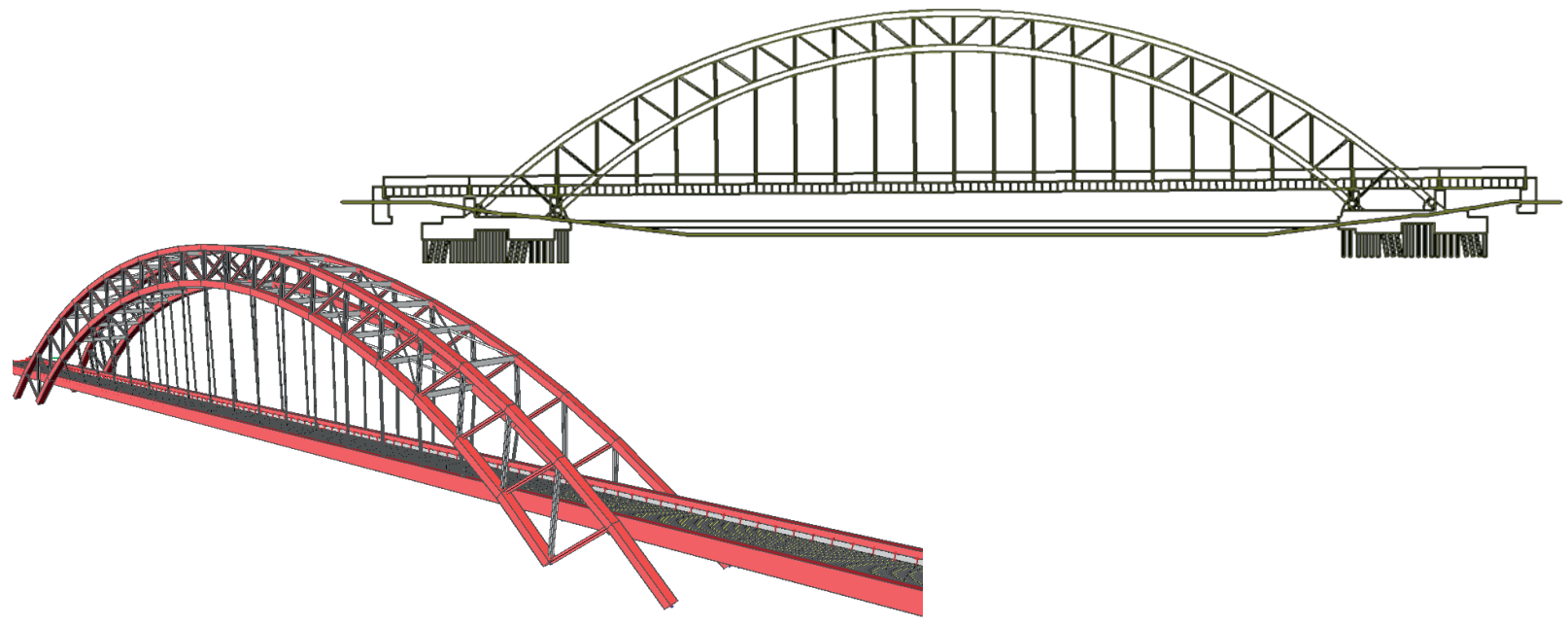

Fig. 2 Longitudinal view and a FEM model of the superstructure - the second proposal

to ensure navigability of Vah Waterway of class $\mathrm{Va}$, at least, had to be necessarily satisfied. In addition, because of the navigable waterway in the future, excavating the river bottom of the value of $1.93 \mathrm{~m}$ had to be taken into account, as well. The small distance from the end switches of the railway station together with request for minimizing the piers in the canal induced the need of twoline bridge. Based on the adopted concept of arch bridges, two alternatives for bridging the water canal were presented in the first design stage.

The first proposal was based on conventional solution, where a set of bow-string arch bridges (Langer's beams) was considered. Four simply supported steel beams reinforced by arches have spans $62.40+124.80+124.80+62.40 \mathrm{~m}$ long, see Fig. 1. The total length of the bridge is $450.65 \mathrm{~m}$. Bottom steel orthotropic deck was designed to redistribute loads from ballast bed to the main girders. Unfortunately, this solution required an establishment of three piers in the canal-basin. Accordingly, to find a compromise with the State Navigation Administration, a splitting shipping space from the original width of $50 \mathrm{~m}$ perpendicular to the river was negotiated into the two parts with the width of $2 \times 30 \mathrm{~m}$. Such solution would allow shipping on both sides of the middle pier.

The second alterative of the proposed draft led into the fixed trussed through-arch bridge, see Fig. 2. This solution had the ambition to bridge the entire main obstacle - the river, with the superstructure of a single bridge span. An interesting structure consists of two truss arches with a span of their lower chord of $240.00 \mathrm{~m}$ and a suspended deck, which continued with two spans of $2 \times 25.00 \mathrm{~m}$ on both ends. The total rise of upper arch chord has the value of $52.60 \mathrm{~m}$. Both arches were designed in inclined planes at a distance of $11.40 \mathrm{~m}$ at the top of the arches and $17.50 \mathrm{~m}$ at the level of bearings. Although expensive, it represents a very courageous design without need for construction of a substructure in the bed of canal.

To choose the most favourable solution from the economic, aesthetic and structural point of view, rather time-consuming negotiations with representatives of the Railway Administration took place. Finally, the first proposed alternative introducing four single-span bridges consisting of stiff beams reinforced by arches and combined with the bottom orthotropic plate decks was found as the better one. Despite of any other arguments, the main reason was clear. The second alternative was more expensive than the first version proposed. Nevertheless, the two middle spans of this chosen two-line railway bow-string arch bridge still belongs to the unique structures in the design practise in our region.

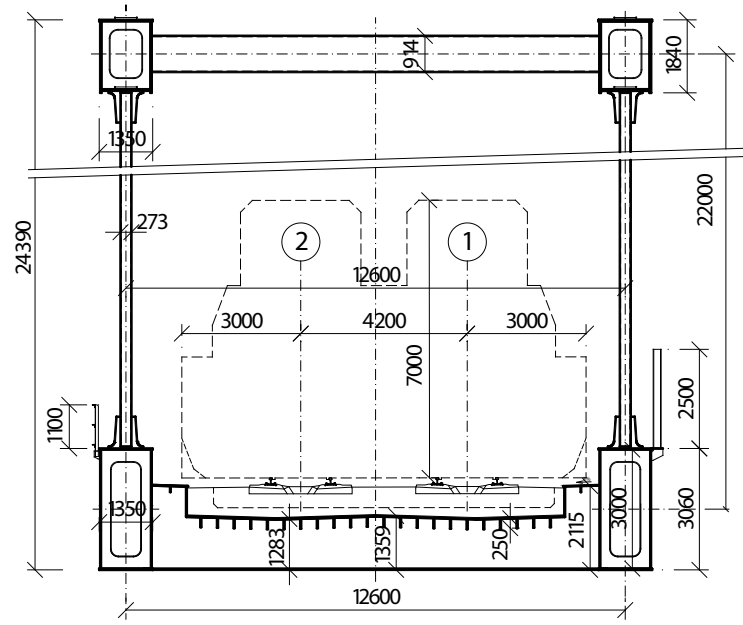

Fig. 3 Cross-section of the superstructure in the middle of the 2nd span

\subsection{Basic parameters of superstructures of the final proposal}

The steel superstructures of two internal fields 2 and 3 (Fig. 3 ) with theoretical spans of $124.8 \mathrm{~m}$ consist of two bow-string arch girders with the lower orthotropic bridge deck and the upper longitudinal bracing. The plate beams are designed from passable 
box-section with external dimensions of $1350 \times 3100 \mathrm{~mm}$. The arches are designed as the circular curved with theoretical rises of 22.00 meters. Above the supports they are centrically connected to the beams of passable box-section with internal dimensions of $1220 \times 1710 \mathrm{~mm}$. The vertical hangers are designed from steel tubes R $273 / 20 \mathrm{~mm}$, filled with concrete C $20 / 25$ in order to increase dynamic resistance to the transverse vibrations.

The steel superstructures of two edge fields 1 and 4 with theoretical spans of $62.4 \mathrm{~m}$ are similar to the previous one. The plate beams are also designed as the passable box-section with external dimensions $1000 \times 2410 \mathrm{~mm}$. Theoretical rises of the circular curved arches are 11.00 meters. Above the supports they are connected to the beams with the eccentricity of $460 \mathrm{~mm}$. The passable cross-sections of arches have internal dimensions of $900 \times 1020 \mathrm{~mm}$. The vertical hangers are from steel tubes $\mathrm{R}$ 219/17.5 mm, filled with concrete C 20/25.

The superstructures have a bottom steel plate orthotropic bridge deck with continuous ballast bed. The deck plate of thickness $16 \mathrm{~mm}$ is shaped into the profile of ballast bed channel with vertical webs. Flat longitudinal stiffeners located at distances of $420 \mathrm{~mm}$ are designed from plates $25 \times 250 \mathrm{~mm}$. Transverse stiffeners are arranged at distances of $2600 \mathrm{~mm}$ and they have a variable cross-section of an inverted $\mathrm{T}$ shape.

\section{Analysis of the bridge superstructure}

\subsection{Global analysis model}

For the global analysis, the spatial transformation model of the bridge structure given in Fig. 1 was developed using software based on Finite Element Method. Considering the size of the structure, the member finite elements were used for modelling main girders, arches, hangers and upper bracings, respectively. A steel plate of the deck was meshed by 2D shell finite elements. The plate was stiffened by the ribs in the longitudinal and transversal way, approximating in this manner the longitudinal and transversal stiffeners of the deck. Variation of thickness of all plates through the length, the changes of stiffness and all relevant

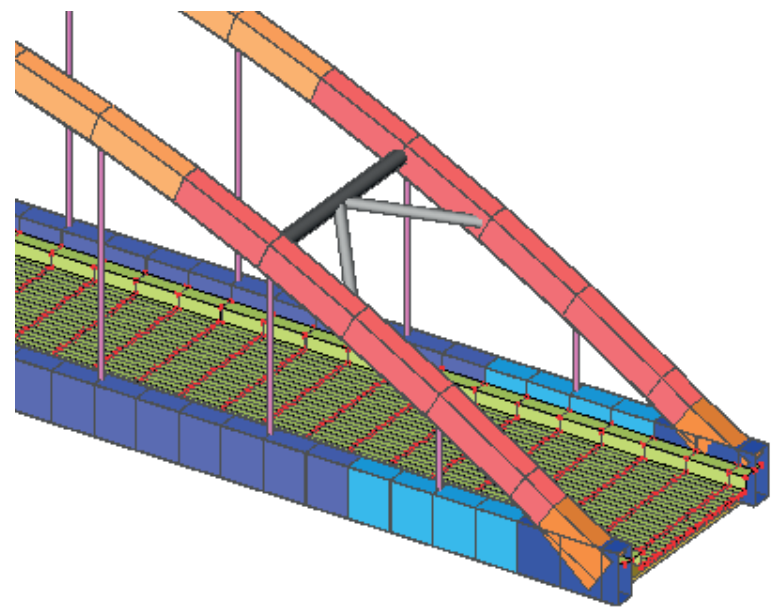

eccentricities were considered in the numerical model, too. Considering the actual structural detail, the arch-to-beam joint were considered as a rigid, while the connections of hangers were approximated by the hinge joints (Fig. 4).

\subsection{Stability of arches}

Firstly, it was necessary to optimise the main dimensions, especially to find the optimal ratio of arc rise to its length. Then, the configuration of upper longitudinal bracings was varied from common truss systems to frame ones. After the preliminary design and optimisation process, more complex static analysis, analysis of stability and dynamic analysis could be performed.

\subsubsection{Variation of upper bracings}

In order to observe an influence of upper longitudinal bracing on the stability of the arches, a parametric study was performed. Different types of the bracing system were incorporated into the spatial computational models of the both bridge superstructures. The first comparative model was considered without any upper bracing system (I). Then, two basic types of upper bracing systems were taken into account: the frame system (II) with different number of cross-beams and the truss system (III) with various arrangements of diagonals. All considered bracing systems are summarized in Fig. 5. Besides, better understanding can be obtained from Fig. 7. In all cases, the bracing members were designed of circular hollow sections. In case of truss bracing system, the slenderness of members did not exceed the value of 150

\subsubsection{Stability analysis}

Implementation of the imperfections as well as the second order effects into global analysis was found as a very time-

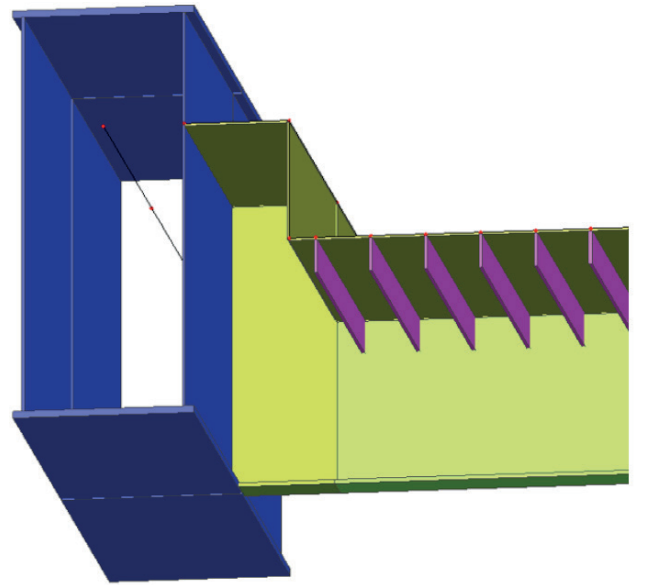

Fig. 4 Detailed look on FEM model visualisation of the longer superstructure 

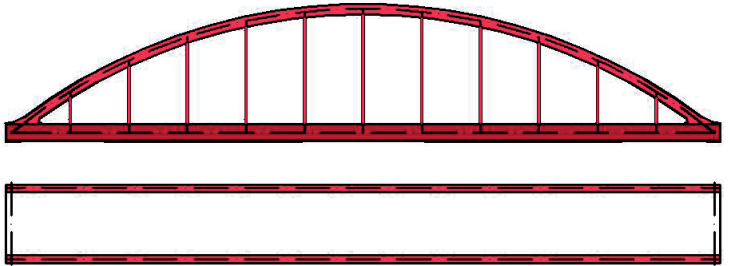

IIa

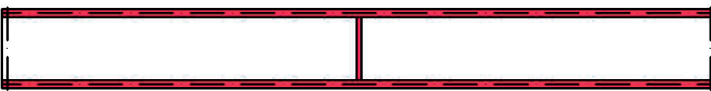

IIb

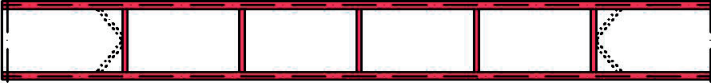

IIc

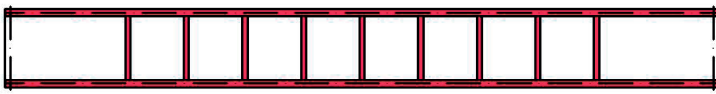

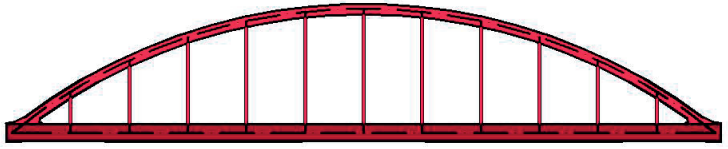

IIIa

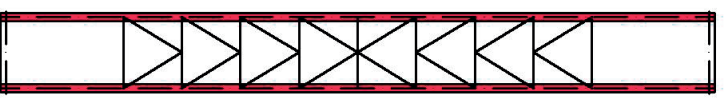

IIIb

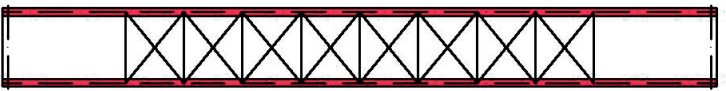

IIIc

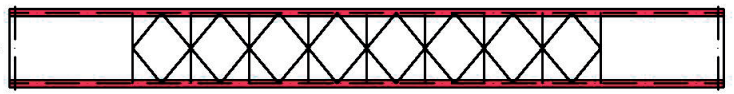

Fig. 5 Considered types of upper longitudinal bracings

consuming procedure because of full geometry models. Therefore, it was decided to take into account the imperfections of arch in the global analysis and the second order effects to allow for during a verification process. Buckling effects can be then included by introduction of equivalent buckling lengths, corresponding to a global eigenmode of the loss of structural stability, particularly the arches. In that case, the first order analysis may be used to find the factor $\alpha_{c r}$, by which the design load should be increased to cause the elastic instability in a global mode.

The critical buckling length $L_{c r, z}$ of arch member for buckling about $z$ axis can be then obtained from the well-known equation:

$$
L_{c r, z}=\pi \sqrt{\frac{E \cdot I_{z}}{\alpha_{c r} \cdot N}}=k_{z} \cdot L_{a r c h}
$$

The unknown parameters in the equation (1) not mentioned hereinbefore are: $E$ - the steel modulus of elasticity; $I_{z}$ - the second moment of area about $z$ axis of the arch cross-section; $N$ - the value of normal force in the arch element, for which the stability is analysed; $k_{z}$ - the coefficient of buckling length for buckling about $z$ axis; $L_{\text {arch }}$ - the theoretical length of arch axis.

Similarly, the influence of deformed geometry, so called "the second order effect" can be expressed by means of multiplying horizontal bending moments in arches determined using the first order theory by the factor $k_{I I}$, according to equation:

$$
k_{I I}=\frac{1}{1-1 / \alpha_{c r}}=\frac{\alpha_{c r}}{\alpha_{c r}-1}
$$

Calculated values of the factors $\alpha_{\mathrm{cr}}$ and $\mathrm{k}_{\mathrm{z}}$ for various bracing systems

\begin{tabular}{|c|c|c|c|c|c|c|}
\hline \multicolumn{3}{|c|}{ Span of the bridge [m] } & \multicolumn{2}{|c|}{62.4} & \multicolumn{2}{|c|}{124.8} \\
\hline \multicolumn{3}{|c|}{ Span-to-width ratio } & \multicolumn{2}{|c|}{5.07} & \multicolumn{2}{|c|}{9.90} \\
\hline \multicolumn{3}{|c|}{ Upper bracings of the arches } & $\alpha_{c r}$ & $k_{z}$ & $\alpha_{c r}$ & $k_{z}$ \\
\hline \multicolumn{2}{|l|}{ Without bracing } & I & 4.57 & 0.31 & 1.76 & 0.33 \\
\hline \multirow{4}{*}{ Frame bracings } & One in the middle & IIa & 5.06 & 0.30 & 1.94 & 0.32 \\
\hline & In every 2nd hanger & $\mathrm{IIb}$ & 5.25 & 0.29 & 2.85 & 0.26 \\
\hline & $\mathrm{IIb}+$ portal diagonals & $\mathrm{IIb}^{*}$ & 5.38 & 0.28 & 3.22 & 0.24 \\
\hline & In every hanger & IIc & 5.46 & 0.28 & 3.43 & 0.24 \\
\hline \multirow{3}{*}{ Truss bracings } & $\mathrm{K}$ - truss & IIIa & 12.61 & 0.19 & 5.69 & 0.18 \\
\hline & $X$ - truss & IIIb & 13.10 & 0.18 & 5.64 & 0.18 \\
\hline & rhombic truss & IIIc & 13.34 & 0.18 & 5.71 & 0.18 \\
\hline
\end{tabular}

* Values for the finally adopted solution are in bold 
The equation (2) is authorised by Eurocode 3 [4] only for values of amplifier $\alpha_{c r}$ higher than 3.0. In-plane buckling of the arches is controlled by tension hangers. This was also confirmed by stability analyses. Moreover, second order effects in vertical direction could be regarded as inessential, because the amplifier to reach the elastic in-plane instability $\alpha_{c r}$ was far above the value of 10.0 in both cases of arch structures.

\subsubsection{Comparison of the parametric study results}

The results of stability analyses of both superstructures stiffened by all aforementioned types of bracing systems are presented and compared in Table 1. Denotation of the particular bracing systems is shown in Fig. 5. As could be expected, the frame bracing system is generally less effective than the truss one [5]. The arch stability is also affected by the span-to-width ratio of the bridge superstructure. The comparison in Table 1 outlines dominant role of rigid model of arch-to-girder connection, as well. Actually, the out-of-plane buckling lengths of non braced arches could be considered under the one third of the theoretical arch length for all analysed cases. When using the truss bracing, the rhombic system seems to be the most effective, but only small differences were observed between particular truss types.

Calculated values of the amplifier $\alpha_{c r}$ from Table 1 are graphically compared in Fig. 6. It is clearly seen that, in the case of shorter spans, the use of truss bracing would significantly stabilize arches. If the span comes longer, the difference between frame and truss bracing is less evident.

The results of stability analyses of the final proposal are illustrated in Fig. 7 in the form of a mode of stability lost.
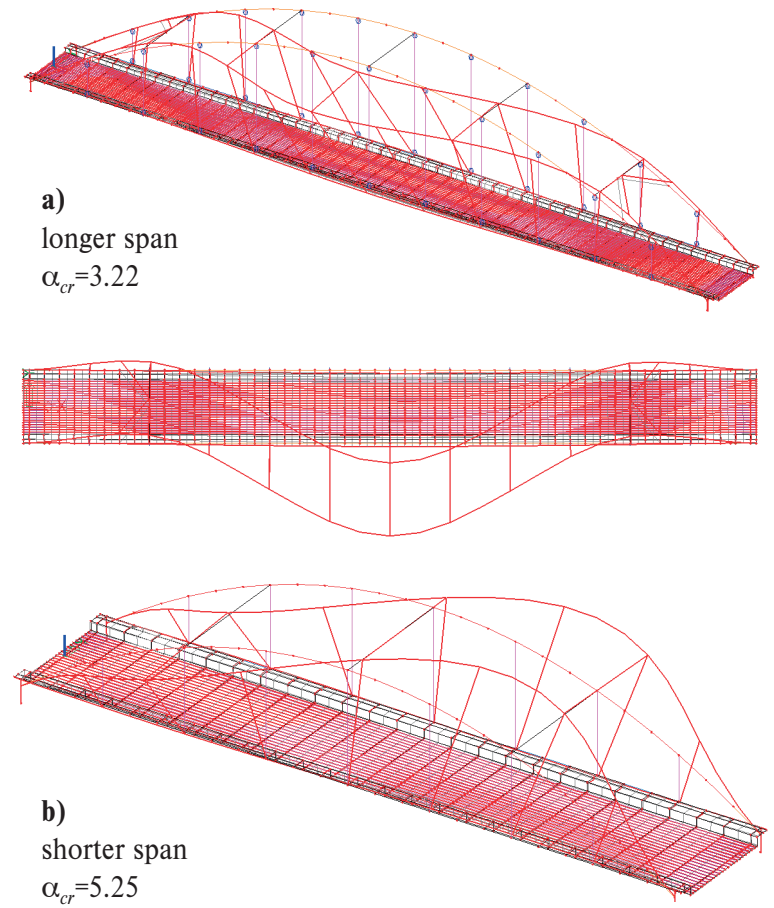

$\alpha_{c r}=5.25$

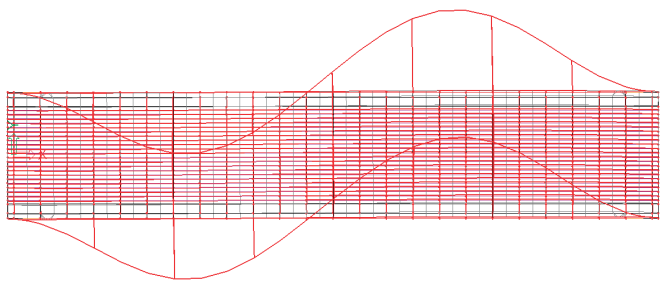

Fig. 7 Shapes of stability lost - bifurcation eigenmodes of the structures: a) for longer spans with $\alpha_{c r}=3.22$; b) for shorter spans with $\alpha_{c r}=5.25$

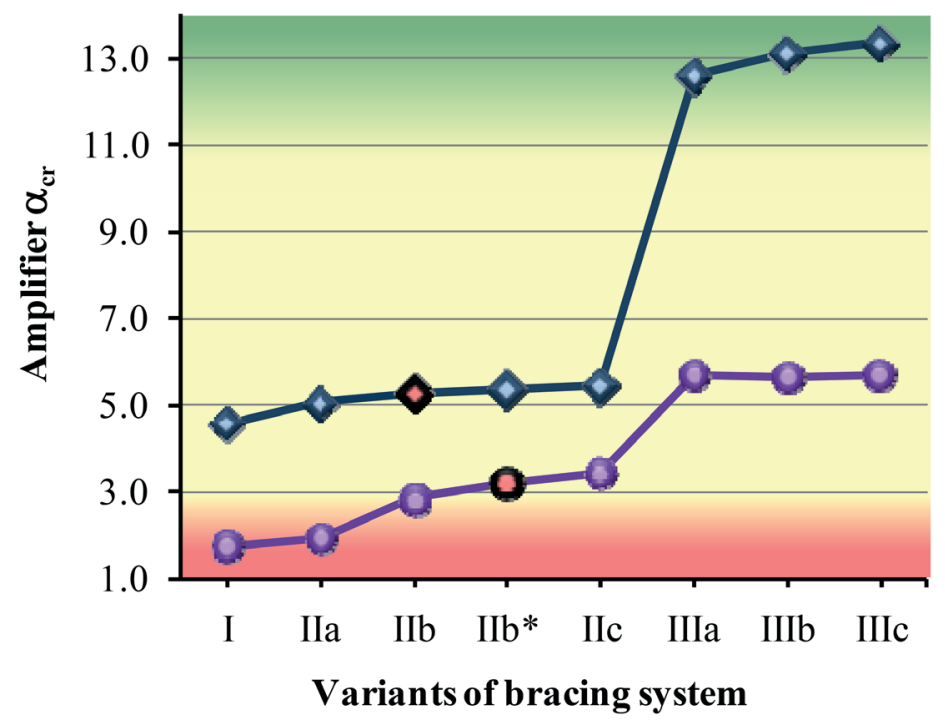

$62.4 \mathrm{~m}$ long span

$124.8 \mathrm{~m}$ long span

I $=$ without bracing

IIa = frame - one in the middle

IIb $=$ frame - in every 2 nd hanger

$\mathbf{I I b}^{*}=$ frame - Ilb + portal diagonals

IIc $=$ frame - in every hanger

IIIa $=$ truss - K-truss

IIIb $=$ truss $-\mathrm{X}$-truss

IIIc $=$ truss - rhombic truss

Fig. 6 Comparison of minimum load amplifiers $\alpha_{c r}$ to reach elastic instability 


\subsubsection{Discussion of aesthetic look of bracings}

The aesthetics and architecture is commonly considered as universal opinion for attractive solution. Upper bracing of bowstring arch bridges is placed on visible part of the bridge and usually plays a dominant role in look of the bridge. In Fig. 8, the arrangement of bracing in the case of the superstructure with longer span $(124.8 \mathrm{~m})$ is compared.

Based on the human nature, many opinions on the best solution would be certainly found. As could be expected, the truss bracing seems to be less attractive. If the frame bracing is applied, it can be stated that the fewer cross members are installed the more beautiful sight is achieved. The mission is if the question: "Which is the nicest bracing?" is the most accurate in the case of the railway bridge not placed just in the middle of a big city. If the ability to stabilise arches is taken into account, the question can be probably turned into "which bracing with high level of stiffness has still acceptable look?"

Finally, the concept of frame bracing in every second hanger (variant IIb) was adopted for the bridge over the Nosicky Canal in Puchov city, where the rigid joint of the box arch to the box crosssection of girder plays very important role in the arch stability. In the case of longer superstructure with theoretical span of $124.8 \mathrm{~m}$, the both portal cross-braces are reinforced with a pair of diagonals in order to increase the stability and to push up amplifier $\alpha_{c r}$ over the value 3.0 (variant $\mathrm{IIb}^{*}$ ).

\section{Conclusion}

A dominant bridge, which is being prepared for construction within the scope of modernisation of corridor lines on the Slovak Railways, is presented in the paper. Because of the space limitation, a special attention was paid only to the stability of arches. The results of the stability analysis show that except of system of bracing, some other parameters are important, as well. The stiffness of joint between the arch and the main girder seems to be also essential. A stiffer box-to-box connection of arch-togirder joint can notable increase the arch stability in comparison with the arch fixed to a common plate I-girder. The span-to-width ratio has significant influence, as well.

From the description of the concept of bridging the Nosicky Canal, the analysis of the structure and its technical parameters, it is clear that the bridge represents a very ambitious and challenging structure. After the successful erection, the bridge will surely go down in history of Slovak bridge building.

\section{Acknowledgements}

This paper presents results of works supported by the Slovak Research and Development Agency under the contract No. APVV-0106-11 and by the Scientific Grant Agency of the Slovak Republic under the project No. 1/0364/12.
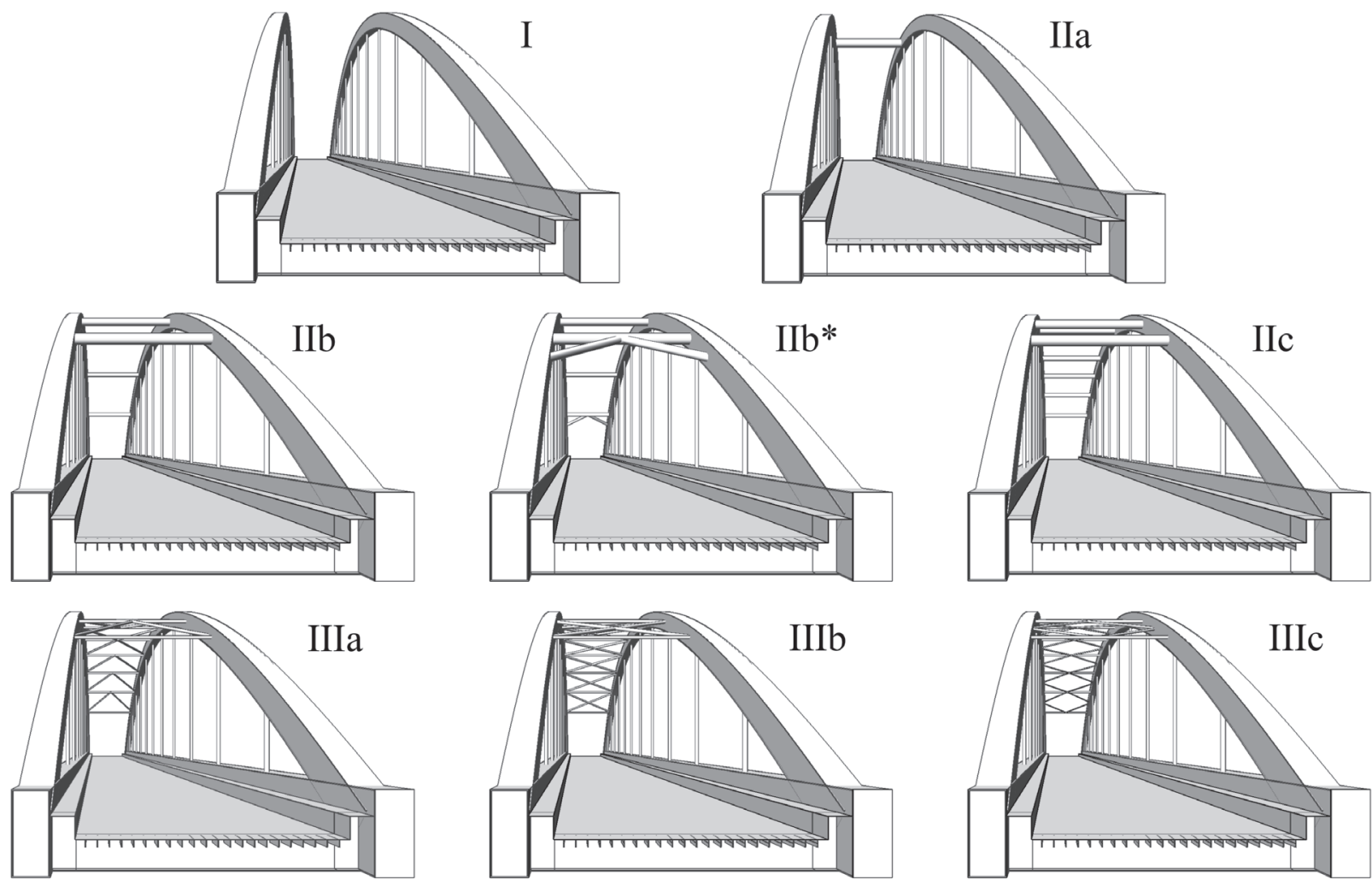

Fig. 8 Aesthetic look of bracings in the case of the $124.8 \mathrm{~m}$ long span superstructure (for denotation, see Fig. 5 and Table 1) 


\section{COMMNICOIIIONS}

\section{References}

[1] IZVOLT, L., KARDOS, J.: Influence of Parameters of Railway Track Construction on Vertical Dynamic Interaction Vehicle/Track, Communications - Scientific Letters of the University o Zilina, vol. 13, No. 3, 2011, pp. 63-70.

[2] VICAN, J., ODROBINAK, J., GOCAL, J., HLINKA, R.: Remarks from Diagnostics and Load Carrying Capacity Estimation of Existing Railway Bridges. Proc. of $8^{\text {th }}$ Intern. Conference on Short and Medium Span Bridges, Niagara Falls, CSCE, 2010, p. 1501/150-9.

[3] VICAN, J., GOCAL, J., ODROBINAK, J., HLINKA, R.: Reconstruction of Bridges at Corridor Lines of the Slovak Railways, Eurostav: Bratislava, vol. 15, No. 9, 2009, pp. 8-12.

[4] STN EN 1993-1-1: Design of Steel Structures. Part 1-1: General Rules and Rules for Buildings, CEN, Brussels, 2005.

[5] DURATNA, P., BOUCHAIR, A., BUJNAK, J.: Analysis of the Behaviour of Steel-concrete Composite Truss, Communications Scientific Letters of the University of Zilina, vol. 13, No. 4, 2011, pp. 46-50. 